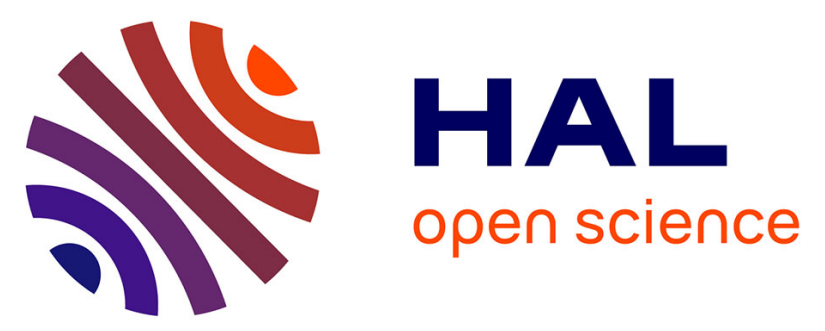

\title{
Simultaneous effects of nutritional and environmental factors on growth and flesh quality of Perca fluviatilis using a fractional factorial design study \\ Jean-Noel Gardeur, Nicolas Mathis, Andre Kobilinsky, Jean Brun-Bellut
}

\section{- To cite this version:}

Jean-Noel Gardeur, Nicolas Mathis, Andre Kobilinsky, Jean Brun-Bellut. Simultaneous effects of nutritional and environmental factors on growth and flesh quality of Perca fluviatilis using a fractional factorial design study. Aquaculture, 2007, 73 (1), pp.50-63. 10.1016/j.aquaculture.2007.09.024 . hal02665288

\section{HAL Id: hal-02665288 \\ https://hal.inrae.fr/hal-02665288}

Submitted on 31 May 2020

HAL is a multi-disciplinary open access archive for the deposit and dissemination of scientific research documents, whether they are published or not. The documents may come from teaching and research institutions in France or abroad, or from public or private research centers.
L'archive ouverte pluridisciplinaire HAL, est destinée au dépôt et à la diffusion de documents scientifiques de niveau recherche, publiés ou non, émanant des établissements d'enseignement et de recherche français ou étrangers, des laboratoires publics ou privés. 


\section{Accepted Manuscript}

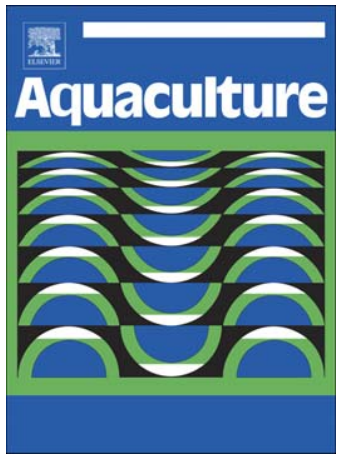

Simultaneous effects of nutritional and environmental factors on growth and flesh quality of Perca fluviatilis using a fractional factorial design study

Jean-Noel Gardeur, Nicolas Mathis, Andre Kobilinsky, Jean Brun-Bellut

PII:

S0044-8486(07)00926-X

DOI: $\quad$ doi: $10.1016 /$ j.aquaculture.2007.09.024

Reference: $\quad$ AQUA 627909

To appear in: $\quad$ Aquaculture

Received date: 21 February 2007

Revised date: $\quad 19$ September 2007

Accepted date: 21 September 2007

Please cite this article as: Gardeur, Jean-Noel, Mathis, Nicolas, Kobilinsky, Andre, BrunBellut, Jean, Simultaneous effects of nutritional and environmental factors on growth and flesh quality of Perca fluviatilis using a fractional factorial design study, Aquaculture (2007), doi: $10.1016 / \mathrm{j}$.aquaculture.2007.09.024

This is a PDF file of an unedited manuscript that has been accepted for publication. As a service to our customers we are providing this early version of the manuscript. The manuscript will undergo copyediting, typesetting, and review of the resulting proof before it is published in its final form. Please note that during the production process errors may be discovered which could affect the content, and all legal disclaimers that apply to the journal pertain. 
Simultaneous effects of nutritional and environmental factors on growth and flesh quality of Perca fluviatilis using a fractional factorial design study.

3

$5 \quad{ }^{1}$ Unité de Recherche Animal Fonctionnalités des Produits Animaux, Nancy-Université INRA,

6 MAN, 34 rue Sainte Catherine, 54000 Nancy, France

$7 \quad$ 22 Unité de Mathématiques et Informatique Appliquées, INRA Domaine de Vilvert F-78352

8 Jouy en Josas Cedex, France

9

10

11

\footnotetext{
* Corresponding author: Tel: +33 3833084 47; fax: +33 383323613.

E-mail : jean-noel.gardeur@lsa-man.uhp-nancy.fr (J.N. Gardeur).
} 
12 Abstract

13

Fractional factorial design is a practical approach for studying multiple factors, with a minimum of experimental units. The objective of this work was to study the simultaneous effects of nutritional and environmental factors on both growth and flesh quality of common perch (Perca fluviatilis), a new inland aquaculture species. This study sought answering the two following questions: (i) which combinations of factors allow improving growth, food efficiency, and technological, sensorial and nutritional qualities? (ii) is it possible to simultaneously improve growth performances and flesh quality? In a first experiment, twelve factors ( 7 nutritional and 5 environmental factors) were each tested at 2 levels in a fractional factorial design in 24 independent recirculating $500 \mathrm{~L}$ tanks. The best 4 combinations identified in this first experiment were then validated in a second experiment. The first phase of the multifactorial approach used here allowed revealing emergent information: i) there is a combination of factors that allows reducing both the heterogeneity of the production and the losses of nitrates and phosphates, while preserving good characteristics of growth and quality of fillets; ii) it is possible to improve the quality of the aquatic production system, without decreasing significantly growth efficiency; iii) the effect of a given factor, even such an important one like diet, temperature or target biomass, depends on the levels of the other rearing factor levels, thus the usual reference optimum used for a given factor has no meaning theoretically and can be questioned according to the levels of the other factors which act altogether on the functioning of the rearing system.

The input factor combinations resulting in a significant enhancement of single output variables or several output variables were identified (e.g. improvement of feed efficiency, and/or fillet docosahexanoic acid content). Our results clearly demonstrate a strong interdependence of input factors into the animal rearing system, particularly between 
nutritional and environmental ones.

Keywords: Aquaculture; Nutrition; Growth; Quality; Fractional factorial design; System

\section{Introduction}

Numerous factors are known to influence both fish production and nutritional qualities of the finished product (e.g. fat level, levels of eicosapentaenoic acid (EPA) and docosahexanoic acid (DHA)). Among these factors, several studies have focused on the effects of nutritional factors on growth and flesh quality of fish (e.g. Torstensen et al., 2001). However, the trophic environment constitutes only one of the elements of the fish rearing environment. Indeed, biological individuals and environmental factors define a system, which operates as an input and output transformation. Systems with biological components are complex because they are composed of numerous and various elements with high degrees of interactions (Weisbuch, 2000). Variations of input factors are responsible for modifications of both the system state and the value of the output variables. As in any biological system, these elements are interrelated, so that experimental approaches which take into account only one or a few factors do not fully allow (i) classifying the relative importance of these factors, (ii) evaluating their possible interactions and (iii) determining the combinations of factors that would be required to improve the features of either the production system or the final product or both.

A fractional factorial experimental design allows such a systemic approach, which includes two main phases: the first step corresponds to a screening of numerous and different factors and the second one aims at optimising the process using the highlighted factors of the first 
62 step. If the independent effect of each factor on output variables is usually relatively well

63 known (e.g. the influence of temperature on growth), the influence of the combination

64 between factors and their interactions are still largely unknown. It thus seems relevant to

65 focus on these topics (1st phase of the method) and then search for optima.

66 In this study, the biological model used is perch, Perca fluviatilis. This species has been

67 proposed for diversifying inland aquaculture production for human consumption. The rearing

68 system is composed of recirculated water tanks to control the greatest number of

69 environmental factors. The effects of 12 main factors (biotic and abiotic) were studied on 12

70 output variables during a first experiment. Then, the best 4 combinations identified in the first

71 experiment were validated during a second experiment. This study sought answering the two

72 following questions: (i) Are there combinations of factors (and their levels) which allow

73 improving growth, food efficiency, technological, or sensorial and nutritional qualities? and

74 (ii) Is it possible to improve simultaneously growth performances and flesh quality?

\section{Materials and Methods}

\subsection{Experimental design}

Thirty-six factors (likely to influence the aquatic system) have been studied by a meta

81 analysis of bibliographical data (principal component analysis, 15 experiments, 33 variables

82 and 172 experimental units) to select the main factors which should be studied in priority

83 (unpublished data). The parameters of water quality have an effect on growth only when they

84 reach extreme values. We measure them during the experimentation to prevent that they

85 reach these extreme values. Thus they were not tested in this experiment. According to the

86 results of this meta-analysis and the literature, twelve influencing factors, i.e., four nutritional 
factors at two levels defining 16 diets, three feeding factors and five environmental factors (Table 1) were tested in an initial experiment with a fractional factorial experimental design (Babiak et al., 2000; Ruohonen et al., 2001). The four nutritional factors are lipid content, dietary lipid source, protein source and astaxanthine enrichment. The two tested levels of each factor (Table 1) were defined from data available in the literature (Melard et al., 1996; Fontaine et al., 1997; Kestemont and Baras, 2001; Kestemont et al., 2001; Xu et al., 2001; Mathis et al., 2003). A full factorial study of 12 factors at 2 levels, entails $2^{12}(4,096)$ possible combinations. Fractional factorial studies have varying degrees of resolution, defining different aliasing structure (confounding between main effects and interactions effects; Butler, 2005). In the present study, a fractional factorial design of Resolution IV with 24 experimental units was selected. This experimental design enables an independent estimation of the constant terms and the main effects of factors as well as a group estimation of each of two-factor interactions (Chen and Cheng, 2000). Of the 4096 possible combinations, 24 were tested and thus the 4,072 remaining combinations were estimated in silico from the measured effects. The resolution IV used here was obtained by doubling its opposite, i.e. the resolution III of Plackett \& Burman's design with 12 units at 2 levels (Kobilinsky and Monod, 1995). In practice, we detected discrepancies between the requested food and the actual food provided by the industrial (data not shown), thus we had to modify our experimental design, which resulted in the loss of both orthogonality and IV resolution. Consequently, factor effect coefficients were dependent, their estimation was less precise and there were some confusion between main effects and interactions. Consequently, the interpretation of the main factors effects will be realized in the form of hypotheses according to the probability that they correspond to main effects, alone, or to main effects confused with groups of interactions (thus they will not be presented here). Nevertheless, the first step of the study indicated above 
111 remained valid for both studying the global effect of the 12 combined factors on the 12 output

112 variables and answering the two main questions above.

113 The first experiment was built without replication. In a second step, the reproducibility of

114 the main results obtained in the first experiment was tested. Four factor combinations coming

115 from the experiment 1 were chosen and tested again, with 4 replications.

\subsection{Animals}

All studies were conducted according to the French national legislation on animal care under a personal authorization to J. Brun-Bellut, delivered by the French Agricultural

121 Ministry for conducting animal experimentation (Authorization 03890).

122 The perch used in the experiment 1 , belonging to the same spawning, came from outdoor

123 tanks (i.e. produced in natural conditions of temperature and photoperiod) located at the 124 research station (CEFRA) at Tihange (Belgium). A single batch of 804 fish weighing between

$12530 \mathrm{~g}$ and $85 \mathrm{~g}$ (average $57.6 \pm 0.5 \mathrm{~g}$ ) was graded into 11 weight classes (5 g range). From 126 these classes, 536 fish were distributed into the 24 experimental units (tanks), such that each 127 unit contained fish of similar initial average weight, low or high initial weight heterogeneity 128 and low (25 fish per tank) or high (42 fish per tank) total biomass (Target final biomass of 6 129 and $10 \mathrm{~kg} \cdot \mathrm{m}^{-3}$ ). The target of maximum final biomass of $10 \mathrm{~kg} \cdot \mathrm{m}^{-3}$ corresponds to the 130 potential of these experimental units which are small and without contribution of oxygen. 131 Each of the 24 experimental units was composed of a $500 \mathrm{~L}$ tank made of light blue PVC, 132 operating independently in a recirculated circuit (Fontaine et al., 1996). These tanks were 133 placed into four experimental rooms. Water temperatures were maintained either at $16{ }^{\circ} \mathrm{C}$ 134 (air-conditioned rooms) or at $23^{\circ} \mathrm{C}$ (heating resistors). Tanks were covered with opaque cages 
$13580 \mathrm{~cm}$ high (isolating them from light and outside disturbances) and fitted with a $15 \mathrm{~W}$ neon

136 light and a band automatic feeder.

137 At the end of the first experiment (116 days) fish were sacrificed by thermal shock 138 combined with an overdose of anaesthetic (i.e. phenoxy-ethanol $\left(3 \mathrm{~mL} \mathrm{~L}^{-1}\right)$ added to water at $1390^{\circ} \mathrm{C}$.). Measurements were carried out on 15 individuals randomly chosen in each tank in the 140 population with a final weight ranging between the average $\pm 2 \mathrm{SD}$.

141 In the second experiment (129 days), fish at the larval stage were obtained from a fish farm

142 in Lorraine (Pisciculture 1'Huillier, Gellucourt, Moselle, France). They were then reared in 143 our laboratory facilities until their mean weight was $38.3 \pm 0.5 \mathrm{~g}$. All other conditions are as 144 the same to those presented above.

2.3. Diet

The 16 experimental diets corresponded to four crossed nutritional factors (lipid content, 149 lipid source, protein source, astaxanthine enrichment (Table 2) with two levels for each factor. 150 Two levels of feeding were established, $22.45 \%$ (limiting feeding) and $30.67 \%$ of body 151 weight $^{-0.68}$ (ad lib feeding, Melard et al., 1996; Mathis et al., 2003). During the first 152 experiment, growth was not very important (50 to $100 \mathrm{~g}$ ), so feeding rate remained unchanged. 153 A regular adjustment of feeding quantities with time was made (three adjustments).

2.4. Measurements, calculations and analyses

Among the 47 outputs, only 12 which were the most explanatory in the principal component analysis are presented in the table 3. During rearing, water temperature and oxygen content were monitored daily after the first feeding period. Ammonium ion and 
160 nitrites $\left(\mathrm{N}-\mathrm{NH}^{4+}\right.$ and $\left.\mathrm{N}-\mathrm{NO}^{2-}\right)$ were measured twice a week (Eaton et al., 1995) and nitrate and

161 phosphate contents weekly. The contents ammonia, nitrites, nitrates, dissolved oxygen of each

162 tank never exceeded the values threshold likely to disturb the growth of fish.

163 As both whole fish and flesh colour are important quality criteria for consumers, and

164 Mathis et al. (2000) showed that reared and wild fish fillets are easily discriminated by colour

165 differences, different measurements of colour were made on fresh fish using a chromameter

166 (Minolta CR 300). The data obtained are expressed in Cartesian coordinates in the system L,

$167 \mathrm{a}^{*}, \mathrm{~b}^{*}$ according to the method suggested by the International Lighting Committee (Kuehni

168 1976). Measurements were conducted on the inside surface, in the thickest antero-dorsal

169 region of the fillet. Colour measurements were realized on two superimposed filets of the

170 same fish (Mathis et al., 2003). Measures were taken twice in two parts separated by about 2

$171 \mathrm{~cm}$. For skin and fin colours, three series of duplicate measurements were realized: the first

172 measure was done on the lower part of the caudal fin, the second on the $3^{\text {rd }}$ stripe in the dorsal

173 section, and the third between the $2^{\text {nd }}$ and $3^{\text {rd }}$ stripe, in the upper third of the fish.

174 Fillet samples were stored frozen under vacuum at $-80^{\circ} \mathrm{C}$ until analyses. Then, the fillets

175 were ground and homogenized. Total lipids from diet and from tissues (muscle, liver, adipose

176 tissue) were extracted in duplicate according to Folch et al. (1957) modified by Chen et al.

177 (1981) using dichloromethane instead of chloroform as solvent. Fatty acid methyl esters from

178 total lipids were prepared by acid-catalyzed transmethylation according to Santha and

179 Ackman (1990) and analyzed using a gas chromatograph equipped with a DB Wax. Helium

180 was used as carrier gas $\left(0.9 \mathrm{~mL} \mathrm{~min}^{-1}\right)$. Fatty acid methyl esters were identified by comparison

181 with known standard mixtures (Sigma, France) and quantified using a computer.

182

183

2.5. Statistical analyses 
To analyze the global effect of combinations on output variables, we performed a first

186 principal component analysis (PCA) using Spad v.6.5 software on the data comprising the

187 system inputs (line $=24$ combinations of rearing conditions; column $=47$ outputs). Twelve

188 outputs were selected and used in a final PCA (line $=24$ combinations of rearing conditions;

189 column $=12$ outputs variables). This 12 outputs were (1) the final fish weight (Wf), (2) the

190 produced biomass (Bio) and (3) the deltaCV, which reflect the volume and heterogeneity

191 (recurring problems in aquaculture) of the production respectively (4) the feed efficiency

192 (FE); (5) the gonadosomatic index (GSI) which reflects the gonadal development; (6) the fillet

193 yield (Yff); (7) the losses of both nitrogen and (8) phosphorous (LN and LP, environmental

194 variables); (9) the brightness of the fillet (Bf), (10) the caudal fin red-green component $\left(\mathrm{a}^{*} \mathrm{c}\right)$,

195 (11) the lipid content in the fillet and (12) the DHA contents (\%Lf, DHA; nutritional 196 variables).

197 Each experimental combination of input factors was also assigned a global score of interest 198 on the output variables. This global score was calculated from the results obtained on each of 199 the 12 output variables of the system. The calculation was based on a transformation of the 200 uncorrected result of each output, in centred reduced output.

201 The 4,072 non-tested combinations were estimated using aliases of significant estimations 202 effects of factors and their interactions (Planor software, INRA).

203 Data of the second experiment were analysed by balanced one way ANOVA with 12 204 residual df (degrees of freedom) (GLM and Univariate Procedures, SAS ${ }^{\circledR}$ 9.1.3). Means were 205 compared using the test of Newman-Keuls $(P<0.05)$ When non normality distribution was 206 observed on the residual, Kruskal-wallis test was used.

\section{Results}


Fish survival between the 24 tanks was $93 \pm 6 \%$. It corresponds to usual results in our

211 experimental conditions. Results of the experiment 1 are presented in the Table 4. The lowest

212 variability is for the output DHA, Fillet final yield and especially Brightness fillet $(\mathrm{CV} \leq 12$

$213 \%)$. On the other hand the dispersal is very high for the following variables: caudal fin red-

214 green component end, GSI, deltaCV and Loss of nitrogen (CV $\geq 78 \%)$.

\subsection{Results by combination}

Results vary greatly according to the output considered. For example, combination C21 yielded the highest fillet level of DHA (51.1\%), a desirable nutritional feature for human consumption, yet the growth performance of this group was very low (Table 4). The highest

221 final fish weight was obtained in the combination C24, in which both the fillet lipid and DHA contents were also higher than the average of the 24 combinations. On the other hand, the nitrogen and phosphate losses were fairly high with an average fillet yield. The combination

$224 \mathrm{C} 1$ had close characteristics and its $4^{\text {th }}$ rank of produced biomass is obtained with a low level 225 of initial biomass.

226 Combination C9 was among those that gave the highest growth ( $2^{\mathrm{d}}$ highest fillet biomass) 227 with the additional advantage of decreasing the variability of fish weight $(-21 \%)$. On the 228 opposite, combination C24 would be undesirable, because it increased the variability of fish 229 weight by $42 \%$. Furthermore, combination C9 had high fillet yields, and low nitrogenous 230 water pollution. However, DHA fillet content of fish raised in the combination C9 was lower 231 compared to the other combinations which had a high final weight. 
The combination C9 is ranked $1^{\text {st }}$, particularly due to the large and homogeneous produced

236 biomass, the high fillet yields and the low nitrogenous water pollution (Table 4). The

237 combinations in $2^{\mathrm{d}}$ rank (Combination C8) had fairly similar results but with a high DHA 238 content and a low produced biomass, due to the low level of initial biomass.

239 Combination $\mathrm{C} 24$, in $4^{\text {th }}$ rank despite its $1^{\text {st }}$ rank for growth, high feed efficiency and high

240 fillet lipid content was penalized, like the combination $\mathrm{C} 1$, by both its high growth

241 heterogeneity and its high nitrogenous water pollution. The combination $\mathrm{C} 1$ and $\mathrm{C} 14$ had the $2425^{\text {th }}$ and $7^{\text {th }}$ produced biomass, respectively, despite a low level of initial biomass.

\subsection{Evaluation of the global effect of combination by PCA}

The plan 1-2 of the PCA explains $55 \%$ of the inertia (total variance). On the axis 1 (Fig. 1),

except for $\mathrm{C} 24$, but the heterogeneity of growth increased during the experiment, and the combinations.

On the axis 2 (Fig. 1), the combinations C3, C5, C9 and C11 were characterised by the vector $\mathrm{Bf}$ and the modality rapeseed oil lipid source (R): they had a brightness of the fillet higher than the mean (Table 6). On the opposite on this axis, the combinations C23 and C24 were characterised by the vectors LP, \%Lf, DHA, deltaCV, Bio and the modality menhaden oil lipid source (M): they had high phosphorus losses, high lipid and DHA fillet contents with 
260 high increase of growth heterogeneity and high produced biomass, especially for the 261 combination C24.

262 The plan 3-4 of the PCA explains $22 \%$ of the inertia. On the axis 3 (Fig. 2), the

263 combinations $\mathrm{C} 8, \mathrm{C} 10, \mathrm{C} 12, \mathrm{C} 16$ were characterised by the vectors a*c, \%Lf, the modality 264 menhaden oil lipid source (M) and the modality $6 \mathrm{~kg} \cdot \mathrm{m}^{-3}$ target biomass (B4): they had a high 265 red-green component caudal fin and a high fillet lipid content except for C16 (Table 7). In 266 contrast on this axis, the combinations C17 and C22 were characterised by the vectors LP, the 267 modalities rapeseed oil lipid source (R) and $10 \mathrm{~kg} \cdot \mathrm{m}^{-3}$ target biomass (B4): they displayed 268 phosphorus losses higher than the mean.

269 On the axis 4 (Fig. 2), the combinations C9 and C8 were characterised by the vector Yff, 270 DHA and $\mathrm{a}^{*} \mathrm{c}$ : they had a high fillet final Yield with a high red-green component of caudal fin 271 and a high content of DHA except for C9 (Table 8). In contrast on this axis, the combinations 272 C7 was characterised by the vectors deltaCV and LN even though C9 was characterised by 273 GSI: C7 had higher increase of the weight heterogeneity and higher losses nitrogen even 274 though C9 had very high gonadal development.

3.4. Temperature and diet effects

The simple fact of maintaining a high temperature $\left(23^{\circ} \mathrm{C}\right)$ resulted in a blocking of sexual 279 development (tank average GSI at $23^{\circ} \mathrm{C}=1.2, \mathrm{n}=12$ vs. 7.9 at $16^{\circ} \mathrm{C}, \mathrm{n}=12$, Kruskal-Wallis 280 test, $P<0.05)$. When high rearing temperature was combined with a photoperiod of 16 hours 281 of light, blocking was even more complete compared to the high temperature combined with a 282 photoperiod of 8 hours of light $(\mathrm{GSI}=0.5, \mathrm{n}=6$ vs. $1.8, \mathrm{n}=6$, Kruskal-Wallis test, $P<0.05)$. 283 The only case where sexual development began was when a temperature of $16^{\circ} \mathrm{C}$ was 284 combined with 8 hours of light $\left(\mathrm{GSI}=11.4, \mathrm{n}=6\right.$ vs. 4.4 at $16^{\circ} \mathrm{C}$ and 8 hours of light, 
285 Kruskal-Wallis test, $P<0.05)$. As a consequence fillet yields strongly decreased (23.1 vs. 33.3,

286 Kruskal-Wallis test, $P<0.05)$. A temperature of $23^{\circ} \mathrm{C}$ was found in the combinations that gave

287 the 9 best results in terms of final fish weight (Table 4). On the other hand, three other

288 combinations at $23^{\circ} \mathrm{C}$ (i.e. combinations $\mathrm{C} 17, \mathrm{C} 3$ and $\mathrm{C} 22$ ) resulted in lower weights than

289 average. Finally, higher rearing temperature was associated with lower flesh lipid content $(\mathrm{r}=$

$290-0.6, \mathrm{n}=12)$.

291 Because of the use of 16 different diets among the 24 combinations tested, eight diets were

292 used in duplicate (Fig. 3). For example, diet 1 was distributed in the combinations C7 and

293 C15. Fish raised in these combinations were widely divergent with respect to final weight,

294 feed conversion efficiency, and fillet lipid content. Others also differed on DHA content (e.g.

295 diet 3, 6, 9, 15). For these variables, an ANOVA on the diet factor (ddf factor=7 vs ddf 296 residual=8) showed no significant difference while the distances between averages were

297 raised (31 in $72 \%$ of the average). The within variability was very important (30 in $83 \%$ of

298 the total variability) which demonstrates the dominating effects of the rearing factors on the 299 diet effects.

300

301 3.5. Reproducibility of the results

302

303 The second experiment was initiated to confirm the reproducibility of the initial results and

304 thus four combinations were tested (Table 9, Fig. 4). These combinations were C9 and C24

305 from the first experiment, plus two "calculated" combinations, resulting from the

306 extrapolation of the tested combinations of the first study. Combination C24 was selected

307 because it had given both the highest individual live weights and produced biomass, and both

308 high fillet lipid and DHA contents. Combinations C9 was interesting because it had strongly

309 limited the heterogeneity of production (compared to the beginning of the experiment), and 
310 also displayed low nitrogen loss, despite a high rearing density. The third combination $(\mathrm{Cs} / \mathrm{n})$

311 optimized the ratio average on variance (signal noise ratio, Box et al., 1988) for final live

312 weight, GSI, fillet yield, brightness, and caudal fin red green component. The fourth

313 combination (Cest) was selected as it was the best among the 4072 calculated (untested)

314 combinations. These calculations for an output variable used the average of this variable, the

315 effect of the significant factors and their interactions calculated with the experimental matrix.

316 This approach was carried out for the main variables which characterised growth (weight,

317 heterogeneity of the weight and biomass), technological (fillet yield) and nutritional quality

318 (\% Lipids, n-3/n-6 ratio). The selected combination was calculated to approach target values

319 fixed on each selected output variable.

320 Concerning the physiological state of fish, a temperature at $23^{\circ} \mathrm{C}$ coupled to a photoperiod

321 of $16 \mathrm{~L}: 8 \mathrm{D}$ blocked sexual maturity as in the experiment 1 , whatever the combination of other

322 tested input factors. C24, which maximized growth performance during the first multifactorial

323 experiment, was confirmed in this second experiment (best results for the final weight, feed

324 efficiency, produced biomass, fillet lipid and DHA contents, Fig. 4). Combination C9, 325 selected for its low final weight coefficient of variation in experiment 1 , also showed this 326 particular characteristic in the second experiment, while resulting in a high fillet biomass 327 production (Fig. 4). Comparing to the two other combinations, Cs/n and Cest have not 328 particular characteristics.

\section{Discussion}

The average specific growth rate in our two experiments (i.e. 0.4 to $0.6 \% \mathrm{~d}^{-1}$ ) was lower 333 than most of the values already described for perch (Baras et al., 2000; Mandiki et al., 2004), 334 albeit these authors worked with lower average weight fish. Other factors such as the choice 
335 of individuals in the population at the beginning of the experiment, and fairly low rearing

336 densities could also explained these lower performances. The growth rates were lower than

337 those initially expected, thus the proposed food was not always entirely consumed, even with

338 the lowest rate. On the other hand inter combination growth rates variability remained high

$339(\mathrm{CV}=31 \%)$ and a technology transfer of these main results in industrial rearing conditions

340 with a high SGR (SGR>3\%) and high biomass confirmed them (AQS F7 2001 report,

341 Ministère de la Recherche, France). Thus we can conclude that the main results of this study

342 are not affected by the experimental low growths.

344 4.1. Aims to improve fish process

346 The improvement of fish production system could concern either total production,

347 productivity, environmental impacts, technological or nutritional qualities of final products.

348 For species which, like perch, stored all their energy in the viscera, estimation of growth

349 performances based on the produced fillet is therefore more relevant at the production level

350 than performances based on total weight. Limiting the heterogeneity of the final product

351 would also be an asset. The current environment of animal production is influenced by both

352 concerns about the environmental impact of agricultural systems, the animal welfare and the

353 requirements of the society. For these reasons, decrease of $\mathrm{N}$ and $\mathrm{P}$ discards in effluvia from

354 production systems, or restricted density of animals in rearing systems, may be added to the

355 list of aims to be taken into account. The product must be attractive, and in this case the

356 colour features of the whole fish and fillets are influent factors for consumers. Finally, fatty

357 acid composition of food has recently become a very high issue for consumers, since some

358 fatty acids cause potential health problems (e.g. trans fatty acids) while others display possible 
health benefits (e.g. long-chain-polyunsaturated fatty acids). All these features could be taken

360 into account with such a multifactorial approach.

361 The data produced here enables the selection of pertinent production input variables

362 according to a given set of specific aims. For example, combinations C24 and C9 provided

363 the best growth performance and low growth heterogeneity, respectively. If the main

364 objective is to have a high weight and nutritional value, combination C24 should be chosen. If

365 the aim is to obtain a high produced biomass with more homogeneous products and better

366 fillet yield while limiting the nitrogenous releases, the combination C9 should be used. For

367 high fillet DHA content, it would be necessary to choose the combination C21. In terms of

368 efficiency of the rearing system, the combination C9 had very competitive growth

369 performances, with decreased weight heterogeneity, high fillet yield and low nitrogenous

370 losses. Its fillet lipid and DHA levels were near the average of the experiment. The

371 combination $\mathrm{C} 21$ had the highest DHA content, but this was gained at the expense of poorer

372 growth than the average. It thus seems possible to have excellent growth and production

373 characteristics without too much sacrifice of DHA levels, yet not vice versa.

374 Solutions like the combination C24 or C9 were not unique, the combinations C1, C7, C16

375 and C14 appeared near to C24 on the axis 1 (Fig. 1) and had the same major characteristics.

376 For example, in a context of preserving fish welfare or extensive livestock picture, the

377 combinations $\mathrm{C} 14$ or $\mathrm{C} 16$ could be an alternative since the fish biomass per unit of volume is

378 lower than results obtained with the combinations C7 and C24. Likewise the combination C8

379 represents an alternative with low rearing density as compared to the combination C9 (Fig. 2).

381 4.2. Interactions among production inputs 
Each tested combination in the current study represents a complex set of linked inputs. To

384 our knowledge, this is the first multifactorial study ever done on fish rearing to test

385 simultaneously so many factors. Thus, it is not easy to compare our results to other more

386 traditional results obtained in fish or other animal species.

387 Torstensen et al. (2001) realized the same approach but with only nutritional factors on 388 Atlantic salmon (Salmo salar) for the investigation of effects of dietary lipid content and pro389 and antioxidants on lipid composition: the FA composition did not differ significantly 390 between the 16 diets and none of the measured responses were affected significantly by the 391 two-factor interaction effects. Our results showed that nutritional effects are strongly 392 dependent to other environmental factors. They revealed potential interactions between 393 nutritional and non-nutritional factors. Different rearing conditions may alter chiefly the 394 outcomes in groups of fish fed identical diets. One of the most striking results obtained in the 395 present study is the degree to which performance of any diet was conditioned by other 396 features of the production system. It was indeed possible to observe either excellent or bad 397 growth for a given diet, or to obtain fish raised on a given diet displaying widely divergent 398 product quality or nutritional features. Interactions between nutritional and environmental 399 factors as highlighted in the present study may explain some contradictory results in the 400 literature where only one or a few factors are tested (e.g. López-Bote et al., 2001, Kaushik et 401 al., 2004).

402 The interdependence of the many input factors was also demonstrated concerning the 403 relation usually proposed between temperature and growth. The temperature accepted for 404 optimal growth of perch is $23^{\circ} \mathrm{C}$ (Mélard et al., 1996), but our results stemming from a 405 multifactorial approach allowed demonstrating that this is conditional and dependent on other 406 factors. Indeed, some combinations at $16^{\circ} \mathrm{C}$ (combinations $\mathrm{C} 6$ and $\mathrm{C} 23$ ) yielded very high 407 produced biomass ( $>1070 \mathrm{~g})$. By contrast, combinations $\mathrm{C} 3, \mathrm{C} 17$, and $\mathrm{C} 22$, with the same 
408

409

410

411 dependent on the levels of other factors. Nevertheless, low temperature did not block sexual development and this effect was more marked with a limited photoperiod, in accordance with

413 the available literature (Migaud et al., 2002). There is, in this case a risk of gonadal 414 development that could compete with growth.

415 In the future, other factors may be tested. For example, light intensity has been considered 416 to play a little role in the performance of growing perch (Jourdan et al., 2003), however this 417 does not guarantee that this factor cannot interact with others in the same manner as observed 418 here for temperature. More than two levels for each factor could be tested, taking into account 419 that the effect of each factor is not always linear. Our fractional factorial approach with 420 multiple factors at two levels represents the first step of screening, in a series of more 421 advanced and detailed experiments to find the optimal operational conditions. This could 422 require either testing the most relevant factors but with a number of levels higher than two 423 (second phase by response surface design). Another way would be by modelling the results of 424 these effects to simulate the behaviour of this system of rearing and carry out in this way a 425 virtual experiment to facilitate targeting specific methods to be checked in vivo. The analysis 426 of significant effects and interactions would thus allow taking into account the relevance of 427 tested levels in this initial approach.

\section{Conclusion}

This study showed that it is possible to improve the quality of the aquatic production 432 system, without too much decreasing growth efficiency. The multifactorial approach used 
433 here allowed revealing emergent information: i) there is a combination of the factors

434 particularly interesting which enable reducing the heterogeneity of the production and the

435 losses of $\mathrm{N}$ et $\mathrm{P}$, while preserving good characteristics of growth and quality of fillets; ii) the

436 effect of a given factor, even such an important one like diet, temperature or target biomass,

437 depends on the levels of the other rearing factor levels, thus the usual optima for a given

438 factor have no meaning theoretically and can be questioned according to the levels of the

439 other factors which act on the functioning of the rearing system.

440 The generic multifactorial approach applied here to an aquaculture system could be used to

441 other reared animal species.

444 Acknowledgements

446 The authors thank the French Research Ministry which allowed the realization of the work 447 by the attribution of the project AQS F7-2001: System of production and the technological 448 and nutritional quality of the Perch and for their Partnership (Laboratoire INRA de Nutrition 449 des poisons, St Pée sur Nivelle; société TAG; société BioMar; Filière Lorraine d'Aquaculture 450 Continentale).

451 We acknowledge professor V. A. Baracos and F. Teletchea for their comments and 452 corrections. 


\section{References}

Babiak, I., Brzuska, E., Perkowski, J., 2000. Fractional factorial design of screening experiments on cryopreservation of fish sperm. Aqua. Res. 31, 273-282.

Baras, E., Malbrouck, C., Houbart, M., Kestemont, P., Melard, C., 2000. The effect of PIT tags on growth physiology of age-0 cultured Eurasian perch Perca fluviatilis of variable size. Aquaculture 185, 159-173.

Box, G., Shoemaker, A.C., Tsui, K.L., Leon, R., Parr, W.C., 1988. Signal-to-Noise Ratios, Performance Criteria, and Transformations. Technometrics 30, 17-20.

Butler, N.A., 2005. Classification of efficient two-level fractional factorial designs of resolution IV or more. J. Stat. Plan. Infer. 131, 145-159.

Chen, H., Cheng, C.S., 2000. Uniqueness of some resolution IV two-level regular fractional factorial designs. SIAM J. Discr. Math. 13, 571-575.

Chen, I.S., Shen, C.S.J., Sheppard, A.J., 1981. Comparison of methylene chloride and chloroform for extraction of fats from food products. J. Am. Oil. Chem. Soc. 58, 599-601.

Eaton, A.D., Clesceri, L.S., Greenberg, A.E. 1995. Standard methods for the examination of water and wastewater. $19^{\text {th }}$ ed., American Public Health Association, Washington, DC.

Folch, J., Lees, M., Sloane-Stanley, G.H., 1957. A simple method for the isolation and purification of total lipids from animal tissues. J. Biol. Chem. 226, 497-509.

Fontaine, P., Terver, D., Georges, A., 1996. Application of aquariological techniques to an aquacultural intensive fish-rearing process using recycled, warmed water for the production of rainbow trout fry, Oncorhynchus mykiss. Aquacult. Eng. 15, 485-498.

Fontaine, P., Gardeur, J.N., Kestemont, P., Georges, A., 1997. Influence of feeding level on growth, intraspecific weight variability and sexual growth dimorphism of Eurasian perch Perca fluviatilis L. reared in a recirculation system. Aquaculture 157, 1-9. 
479

480

481

482

483

484

485

486

487

488

489

490

491

492

493

494

495

496

497

498

499

500

501

502

Jourdan, S., Fontaine, P., Kestemont, P., Gardeur, J.N., 2003. Influence of light intensity on survival, weight heterogeneity and growth of eurasian perch larvae and post-larvae. Percis III, july, Madison (USA) 20-24.

Kaushik, S.J., Blanc, D., Covès, D., Dutto, G., 2004. Almost total replacement of fish meal by plant protein sources in the diet of a marine teleost, the European seabass, Dicentrarchus labrax. Aquaculture 230, 391-404.

Kestemont, P., Baras, E., 2001. Environmental factors and feed intake: mechanisms and interactions. In : Houlihan, D., Boujard, T., Jobling, M. (Eds), Food intake in fish. Blackwell Science, Oxford, pp. 131-156.

Kestemont, P., Vandeloise, E., Melard, C., Fontaine, P., Brown, P., 2001. Growth and nutritional status of Eurasian perch Perca fluviatilis fed graded levels of dietary lipids with or without added ethoxyquin. Aquaculture 203, 85-99.

Kobilinsky, A., Monod, H., 1995. Juxtaposition of regular factorial designs and the complex linear model. Scand. J. Stat. 22, 223-254.

Kuehni, R.G., 1976. Color tolerance data and the tentative CIE 1976 L*a*b* formula. J. Opt. Soc. Am. 66, 497-500.

López-Bote, C.J., Diez, A., Alvarez, M., Bautista, J.M., Corraze, G., Dias, J., Kaushik, S.J., Arzel, J., 2001. Dietary protein source affects the susceptibility to lipid peroxidation of rainbow trout (Oncorhynchus mykiss) and sea bass (Dicentrarchus labrax) muscle. Anim. Sci. 73, 443-449.

Mandiki, S.N.M., Blanchard, G., Melard, C., Koskela, J., Kucharczyk, D., Fontaine, P., Kestemont, P., 2004. Effects of geographic origin on growth and food intake in Eurasian perch (Perca fluviatilis L.) juveniles under intensive culture conditions. Aquaculture 229, 117-128. 
503 Mathis, N., Feidt, C., Brun-Bellut, J., 2003. Influence of protein/energy ratio on carcass 504 quality during the growing period of Eurasian perch (Perca fluviatilis). Aquaculture 217, 453-464.

506

Mathis, N., Feidt, C., Fontaine, P., Brun-Bellut, J., 2000. Comparative sensory and physical analysis of cultured and wild Eurasian perch (Perca fluviatilis). In : W.A.S. (ed), Aqua 2000, 2-6 may 2000, Nice, fr, Aqua2000, 450.

Mélard, C., Kestemont, P., Grignard, J.C., 1996. Intensive culture of juvenile and adult Eurasian perch (P. fluviatilis): effect of major biotic factors on growth. J. App. Ichtyol. 12, 175-180.

Migaud, H., Gardeur, J.N., Pascal, F., 2002. Induction of out-of-season spawning in female Eurasian perch Perca fluviatilis : Effects of the initial bodyweight and the duration of the warming period on gonadogenesis and spawning. In: Fish Genetics and Reproduction, September 12-13, Brno, Cezch Republic.

Ruohonen, K., Kettunen, J., King, J., 2001. Experimental design in feeding experiments: in Food intake in fish. D. Houlihan, T. Boujard and M. Jobling, Blackwell sciences, 88-107.

Santha, N.C., Ackman, R.G., 1990. Nervonic acid versus tricosanoic acid as internal standards in quantitative gas chromatographic analyses of fish oil longer-chain n-3 polyunsaturated fatty acid methyl esters. J. Chromatogr. Biomed. Appl. 553, 1-10.

Torstensen, B.E., Lie, Ø., Hamre, K., 2001. A factorial experimental design for investigation of effects of dietary lipid content and pro- and antioxidants on lipid composition in Atlantic salmon (Salmo salar) tissues and lipoproteins. Aquacult. Nutr. 7, 265-276.

Weisbuch, G., 2002. Environment and institutions: A complex dynamical systems approach. Ecol. Econ. 35, 381-391. 
526 Xu, X., Fontaine, P., Mélard, C., Kestemont, P., 2001. Effects of dietary levels on growth, 527 feed efficiency and biochemical compositions of Eurasian perch Perca fluviatilis. 528 Aquacult. Int. 9, 437-449.

Fig. 1. Projection of outputs and combinations ( $\mathrm{C} 1$ to $\mathrm{C} 24)$ on the plan 1-2 of the principal

533 components analysis of the table of the 12 output variables and 24 combinations. Axis 1 (a1)

534 inertia 42\%, represents brightness of fillet (Bf), fillet final Yield (Yff), feed efficiency (FE), 535 final body weight (Wf), loss nitrogen (LN), producted biomass (Bio=Biomass final -Biomass 536 initial), differences of coefficient of variation of body weight (deltaCV=CVfinal-CVinitial), 537 Temperature $23^{\circ} \mathrm{C}$, Photoperiod $16 \mathrm{~L} / 8 \mathrm{D}$ and in contrast gonado somatic index (GSI), loss 538 phosphorus (LP), Temperature $16^{\circ} \mathrm{C}$ and Photoperiod 8L/16D. Axis 2 (a2) inertia 14\%, 539 represents brightness of fillet $(\mathrm{Bf})$, rapeseed oil food Lipid source $(\mathrm{R})$ and in contrast fillet 540 lipid content (\%Lf), DHA and menhaden oil food Lipid source (M). The characters in bold are 541 those that are carried by the axes 1 or 2 . combination contributing to the axis $1, \square$ ouput 542 modality contributing to the axis $1, \boldsymbol{\Delta}$ combination contributing to the axis $2, \triangle$ ouput 543 modality contributing to the axis 2, combination contributing to the axis 1 and 2 . The size 544 of the symbols is proportional to the contribution of the variables or modality in the 545 construction of the axis. 
Fig. 2. Projection of outputs and combinations (C1 to $\mathrm{C} 24)$ on the plan 3-4 of the principal

547 components analysis of the table of the 12 output variables and 24 combinations. Axis 3 (a3)

548 inertia 11\%, represents red-green component caudal fin (ac), fillet lipid content (\%Lf),

549 menhaden oil food Lipid source (M) and objective of final biomass $4 \mathrm{kgm}^{-3}$ (B4) and in

550 contrast loss phosphorus (LP), rapeseed oil food Lipid source (R) and objective of final

551 biomass $12 \mathrm{kgm}^{-3}$ (B12). Axis 4 (a4) inertia 11\%, represents fillet final Yield (Yff) and DHA

552 and in contrast gonado somatic index (GSI), loss nitrogen (LN) and differences of coefficient

553 of variation of body weight (deltaCV $=\mathrm{CV}$ final-CVinitial). The characters in bold are those

554 that are carried by the axes 1 or 2 combination contributing to the axis $1, \square$ ouput

555 modality contributing to the axis $1, \boldsymbol{\Delta}$ combination contributing to the axis $2, \triangle$ ouput

556 modality contributing to the axis 2, combination contributing to the axis 1 and 2 . The size

557 of the symbols is proportional to the contribution of the variables or modality in the 558 construction of the axis. 
559 Fig. 3. Evolution of the output according to the replicat for 8 feed used in duplicat. (A), final

560 weight; (B) feed efficiency; (C) fillet lipid content; (D) fillet DHA content. 
561 Fig. 4. Results of the experiment 2. C24 = factor combinations which bester body weight;

$562 \mathrm{C} 9=$ factor combinations which lower body weight heterogeneity; $\mathrm{Cs} / \mathrm{n}=$ signal noise ratio;

563 Cest $=$ estimated combination from 4072 combinations; Wf $=$ final weight; Biof $=$ fillet

564 biomass; $\mathrm{CVwf}=$ coefficient of variation of final weight; Yff $=$ fillet final yield; $\mathrm{FE}=$ food

565 efficiency; \%Lf $=$ fillet lipid content $(\%) ;$ DHA $=$ DHA lipid content $(\%)$; CV $\mathrm{RMSE}=$

566 Coefficient of variation of root mean square error (\%). Means without a common superscript

567 differ $(P<0.05)$.

Table 1. The twelve influencing factors evaluated in the present rearing.

\section{Level}

Factor

$+1+1$

Temperature $\left({ }^{\circ} \mathrm{C}\right)$

Ration level (\%biomass)

Lipid content of diet (\%)

Protein source of diet

Lipid source of diet

Astaxanthine enrichment (\%)

Target final biomass $\left(\mathrm{kg} . \mathrm{m}^{-3}\right)$

Feeding mode

Initial weight heterogeneity

(CV initial weight \%)

Photoperiod (Light:Darkness)

Light spectra

Feeding day. week $^{-1}$
23

Low: 22.45. Weight $^{-0.68}$

21

Fish meal + Soybean meal + Wheat

Rapeseed oil

0.4

10

2 meals

30

15

17

0

6

Menhaden oil

High: 30.67. Weight $^{-0.68}$

Fish meal + Wheat

continuous

16L:8D

8L:16D

Industrial white

Pinkish

7 
571 Table 2. Diet composition (\%)

\begin{tabular}{|c|c|c|c|c|c|c|c|c|c|}
\hline $\mathrm{N}^{\circ}$ & Fish & Soybean & & Menhaden & Rapeseed & Astaxan- & Wheat & Vitaminized & ecithin \\
\hline Diet & meal & meal & rivat & oil & oil & thine & meal & premix* & \\
\hline 1 & 43 & 30 & 14.9 & . & 10.5 & . & 0.78 & 0.42 & 0.4 \\
\hline 2 & 43 & 30 & 14.9 & 10.5 & . & • & 0.78 & 0.42 & 0.4 \\
\hline 3 & 43 & 30 & 14.5 & & 10.5 & 0.4 & 0.78 & 0.42 & 0.4 \\
\hline 4 & 43 & 30 & 14.5 & 10.5 & & 0.4 & 0.78 & 0.42 & 0.4 \\
\hline 5 & 43.5 & 30 & 8.4 & . & & & 0.78 & 0.42 & 0.4 \\
\hline 6 & 43.5 & 30 & 8.4 & 16.5 & & 0.4 & 0.78 & 0.42 & 0.4 \\
\hline 7 & 43.5 & 30 & 8 & • & 16.5 & 0.4 & 0.78 & 0.42 & 0.4 \\
\hline 8 & 43.5 & 30 & 8 & 16.5 & . & . & 0.78 & 0.42 & 0.4 \\
\hline 9 & 60 & . & 28.4 & & 10 & 0.4 & 0.78 & 0.42 & 0.4 \\
\hline 10 & 60 & . & 28.4 & 10 & . & 0.4 & 0.78 & 0.42 & 0.4 \\
\hline 11 & 60 & . & 28 & . & 10 & . & 0.78 & 0.42 & 0.4 \\
\hline 12 & 60 & & 28 & 10 & . & 0.4 & 0.78 & 0.42 & 0.4 \\
\hline 13 & 61 & & 21.9 & . & 15.5 & 0.4 & 0.78 & 0.42 & 0.4 \\
\hline 14 & 61 & & 21.9 & 15.5 & . & . & 0.78 & 0.42 & 0.4 \\
\hline 15 & 61 & ! & 21.5 & . & 15.5 & 0.4 & 0.78 & 0.42 & 0.4 \\
\hline 16 & 61 & . & 21.5 & 15.5 & . & 0.4 & 0.78 & 0.42 & 0.4 \\
\hline
\end{tabular}

573 not available due to industrial property. 
574 Table 3. Measured output variables

Growth variables (mean by tank)

Wf = final body weight $(\mathrm{g})$

Bio $=$ produced biomass $=(\mathrm{Wf}-\mathrm{Wi})$ number of fish

deltaCV $=$ Coefficient of variation of final body weight $(\%)$ - Coefficient of variation of initial body weight (\%)

Physiological variables (mean by tank)

GSI $=$ Gonado somatic index $=100$ gonad weight. $\mathrm{We}^{-1}(\%)$

Feeding variables (mean by tank)

$\mathrm{FE}=$ Food efficiency $=\mathrm{g}$ biomass gain $\cdot \mathrm{g}_{\text {food }}{ }^{-1}$

Technological variables (mean by tank)

Yff $=$ fillet final Yield $=100$ fillet Weight final. $\mathrm{Wf}^{-1}$

Environmental variables (mean by tank)

$\mathrm{LN}=$ Loss nitrogen $=\mathrm{g}$ distributed nitrogen $-(\mathrm{g} \mathrm{N}$ biomass $+\mathrm{g} \mathrm{N}$ in water $)$

$\mathrm{LP}=$ Loss phosphorus $=\mathrm{g}$ phosphorus distribute $-(\mathrm{g}$ biomass $. \% \mathrm{P}+\mathrm{g} \mathrm{P}$ in water $)$

Colour variables (mean by tank)

$\mathrm{Bf}=$ Brightness fillet

$\mathrm{a}^{*} \mathrm{c}=$ caudal fin red-green component

Nutritional variables (mean by tank)

$\% \mathrm{Lf}=$ fillet lipid content $(\%)$

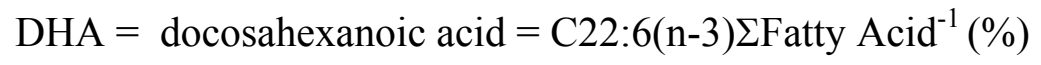




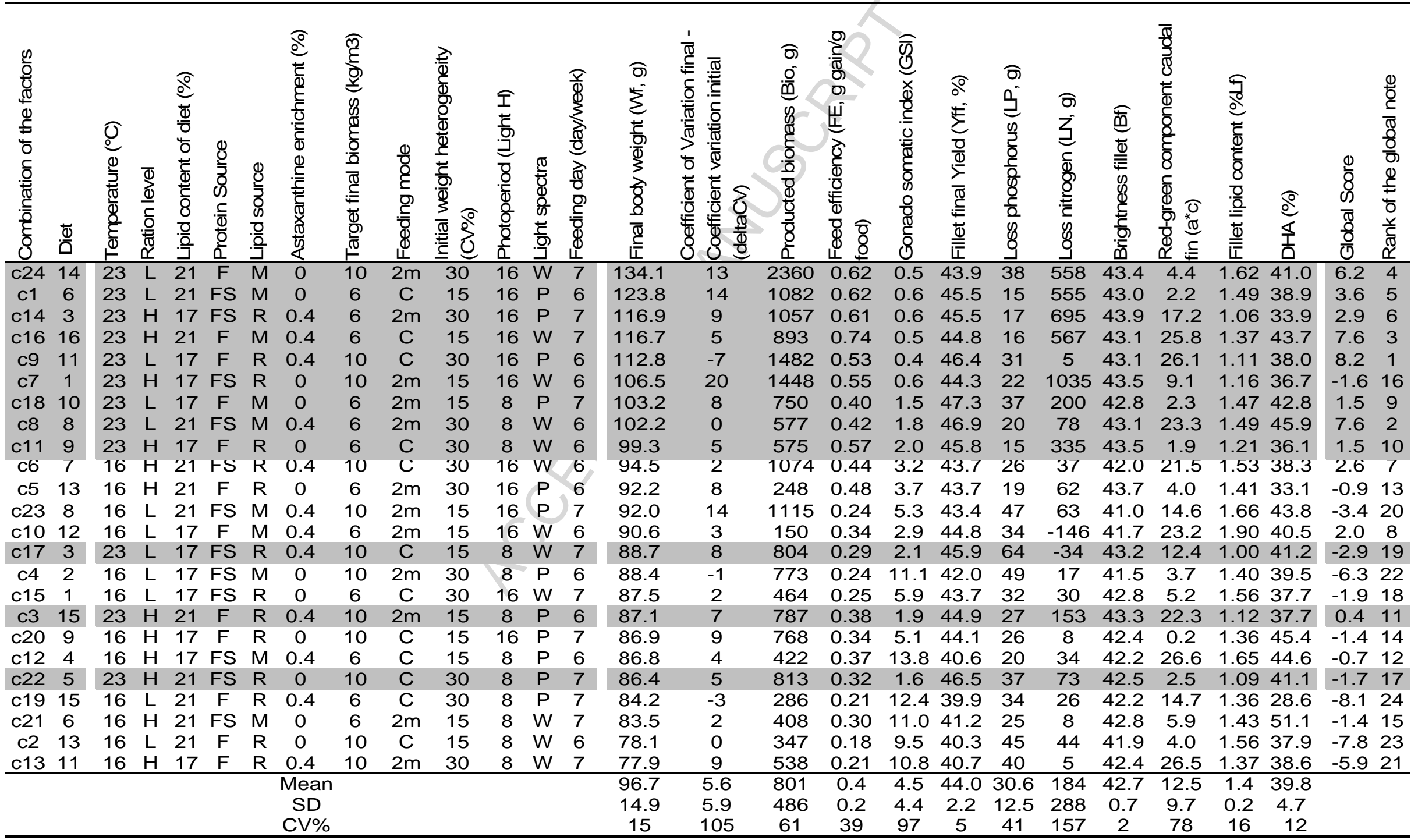


577 Ration level: $\mathrm{L}=$ low, $\mathrm{H}=$ height; Protein source: $\mathrm{F}=$ fish+wheat, $\mathrm{FS}=$ fish+wheat+soybean meal; Lipid source: $\mathrm{M}=$ menhaden oil, $\mathrm{R}=$ rapeseed oil;

578 Feeding mode: $2 \mathrm{~m}=2$ meals, $\mathrm{C}=$ continuous; Light spectra: $\mathrm{W}=$ Industrial white, $\mathrm{P}=$ Pinkish.

579 Global Score: note of interest for each combination from the results obtained on each of 12 output variables of the system. Rank: rank of 580 combinations on the global score.

581 The grey lines correspond to a study temperature of $23^{\circ} \mathrm{C}$. 
Table 5. Characteristics of the combinations by the axis 1

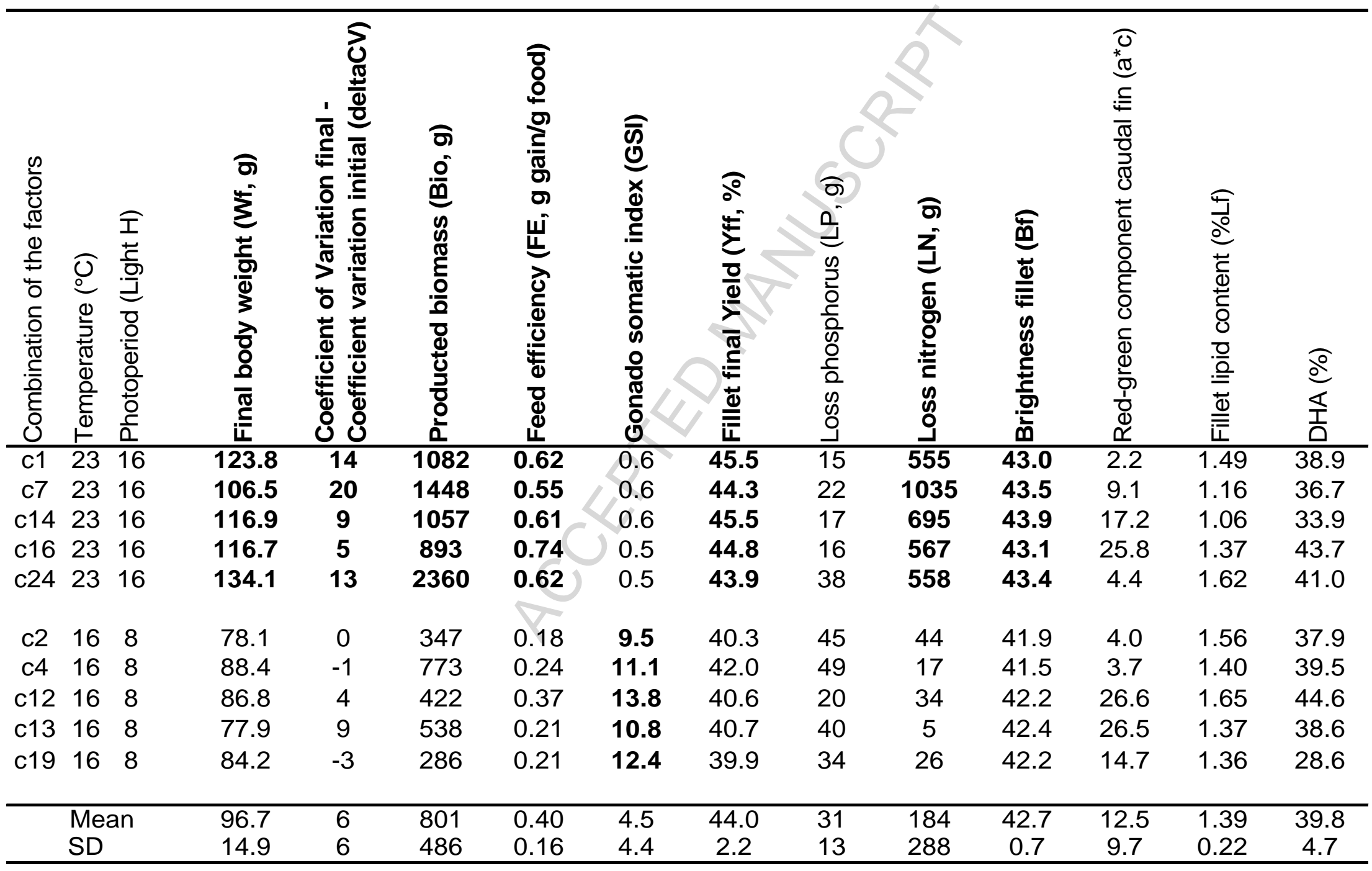

Bold characters correspond to the essential characteristics of combinations. 
Table 6. Characteristics of the combinations by the axis 2

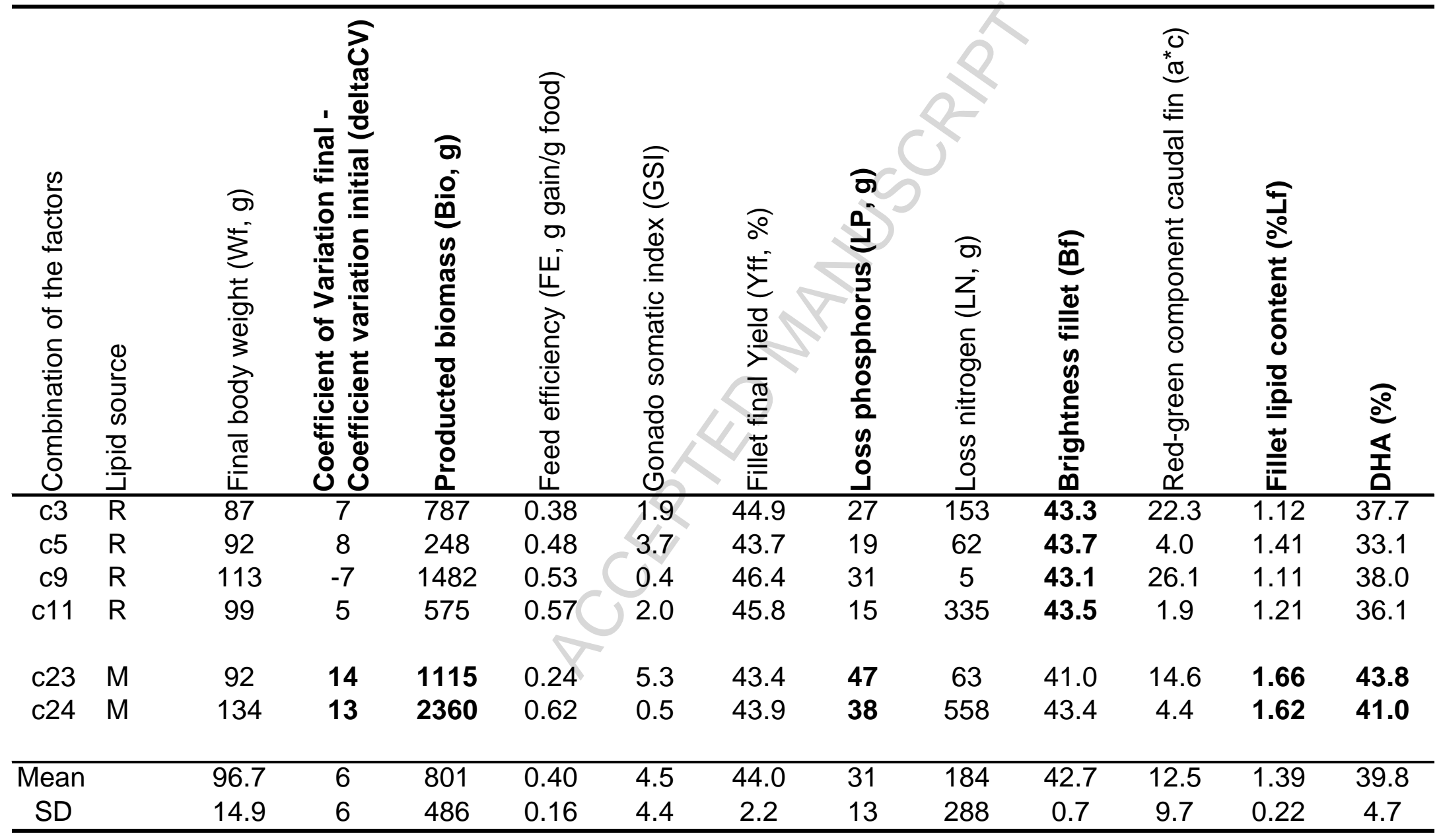

Bold characters correspond to the essential characteristics of combinations. 
Table 7. Characteristics of the combinations by the axis 3

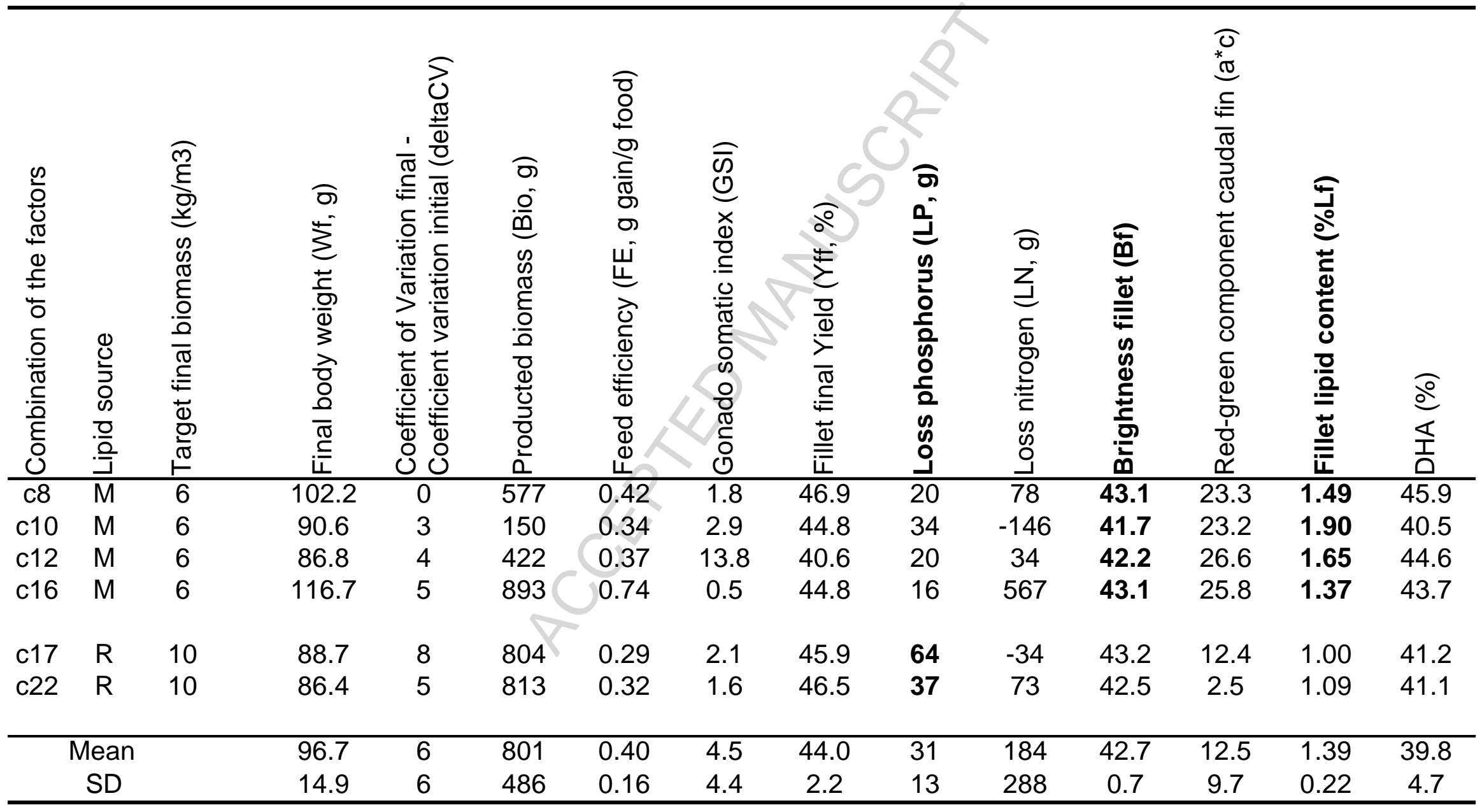

Bold characters correspond to the essential characteristics of combinations. 
Table 8. Characteristics of the combinations by the axis 4

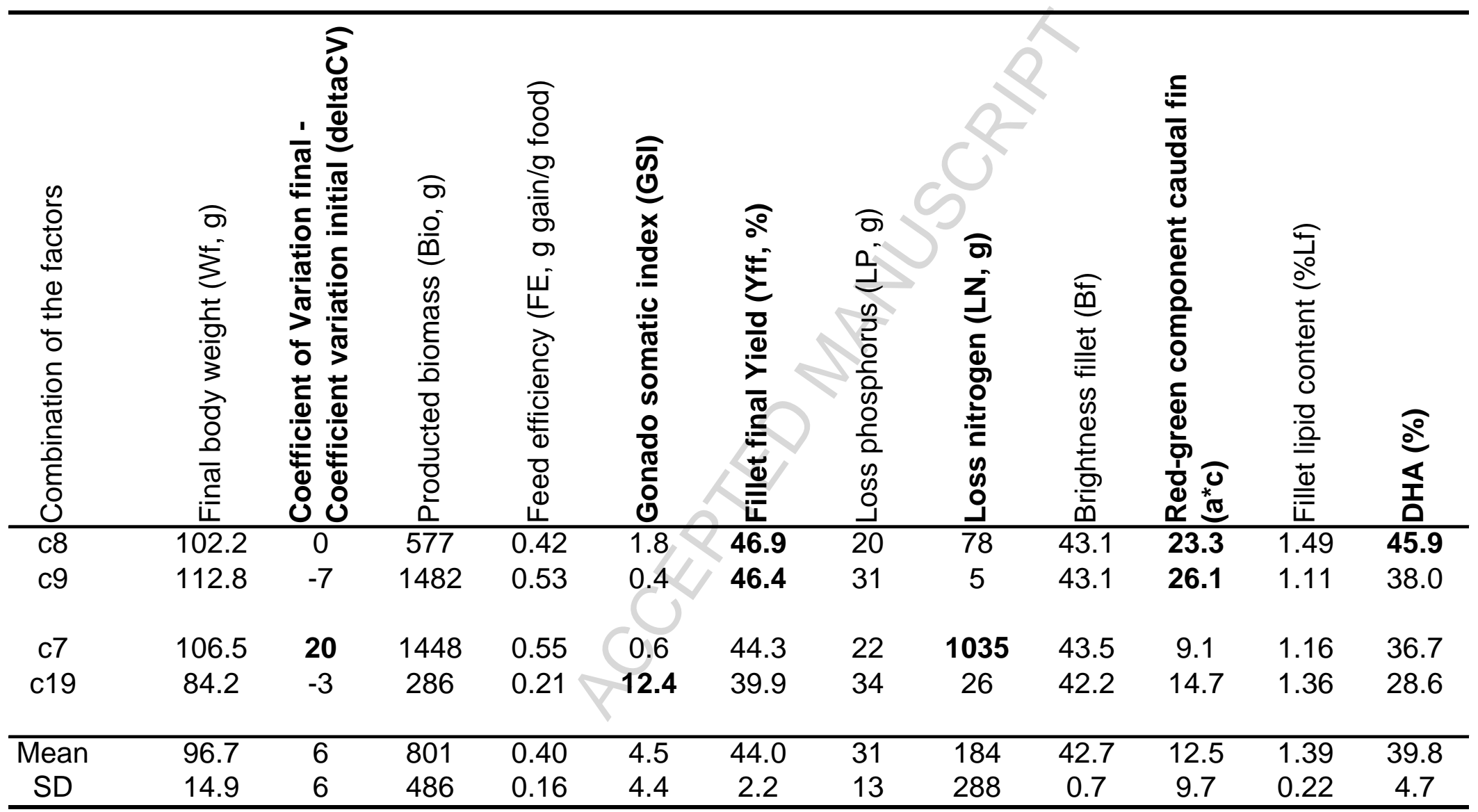

Bold characters correspond to the essential characteristics of combinations. 
594 Table 9. Level of every factor tested in experimentation 2

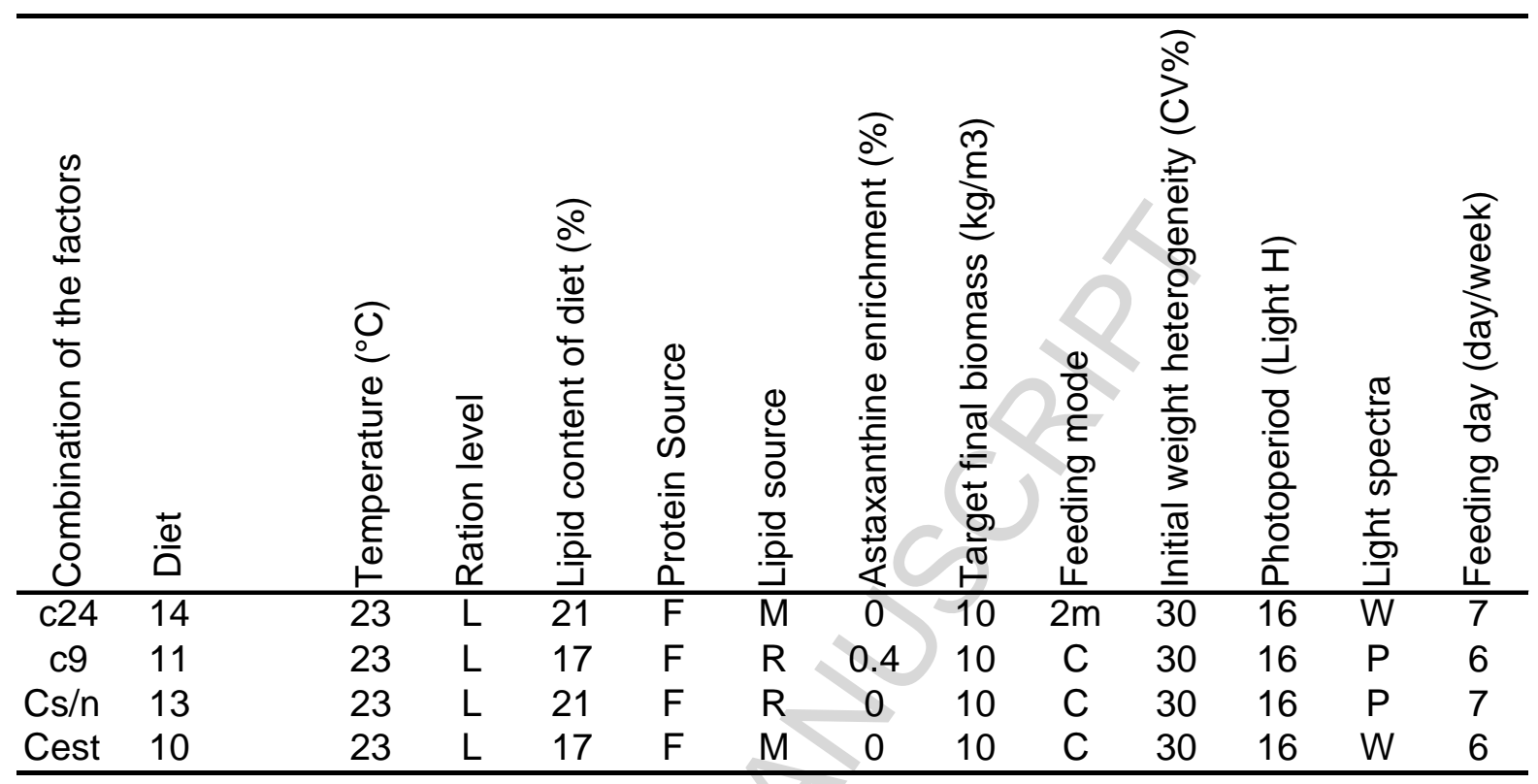

596 Ration level: $\mathrm{L}=$ low; Protein source: $\mathrm{F}=$ fish+wheat; Lipid source: $\mathrm{M}=$ menhaden oil, $\mathrm{R}=$

597 rapeseed oil; Feeding mode: $2 \mathrm{~m}=2$ meals, $\mathrm{C}=$ continuous; Light spectra: $\mathrm{W}=$ Industrial white, $598 \quad \mathrm{P}=$ Pinkish.

599

600

601

602 


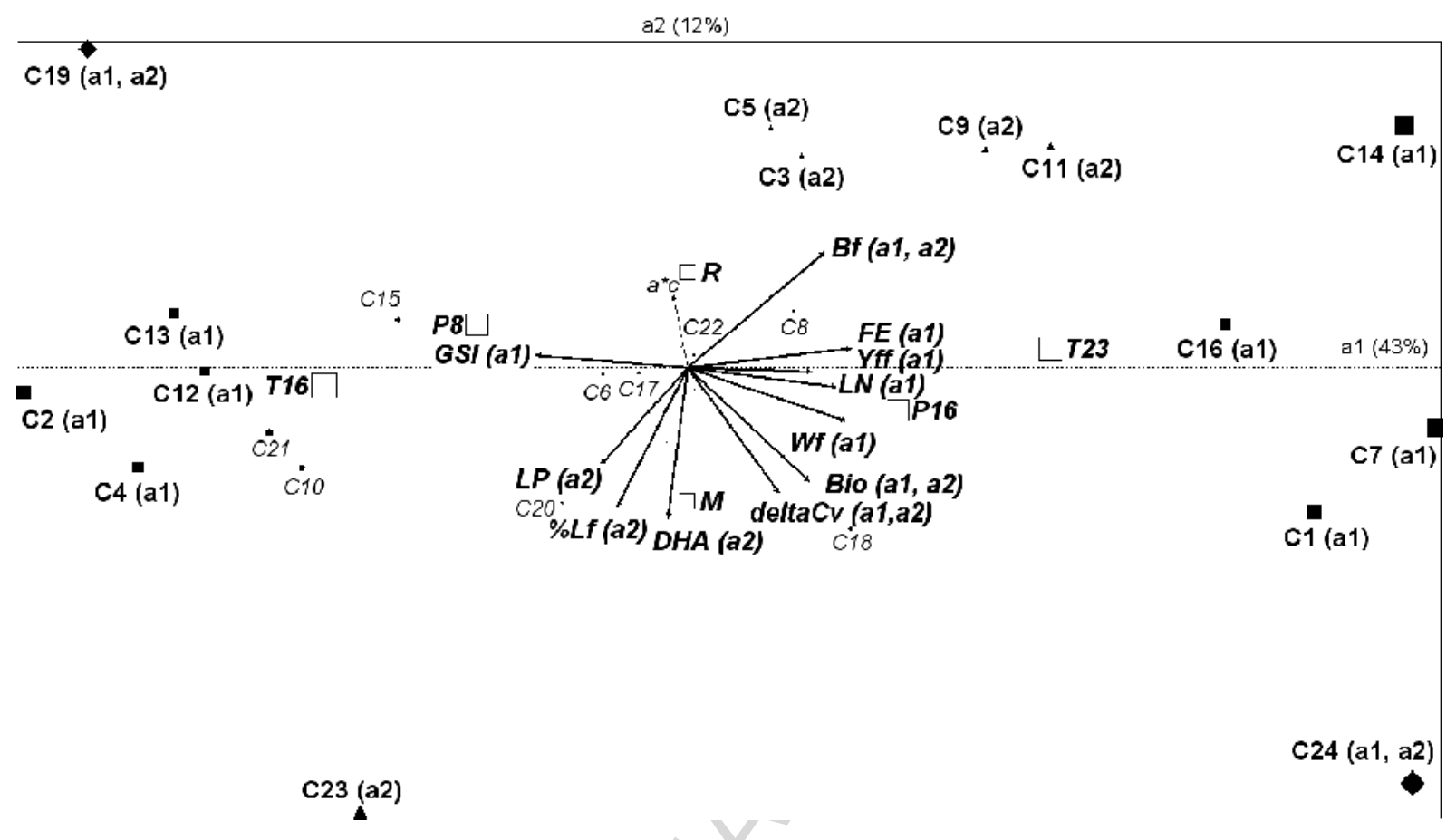

604

605

606

607

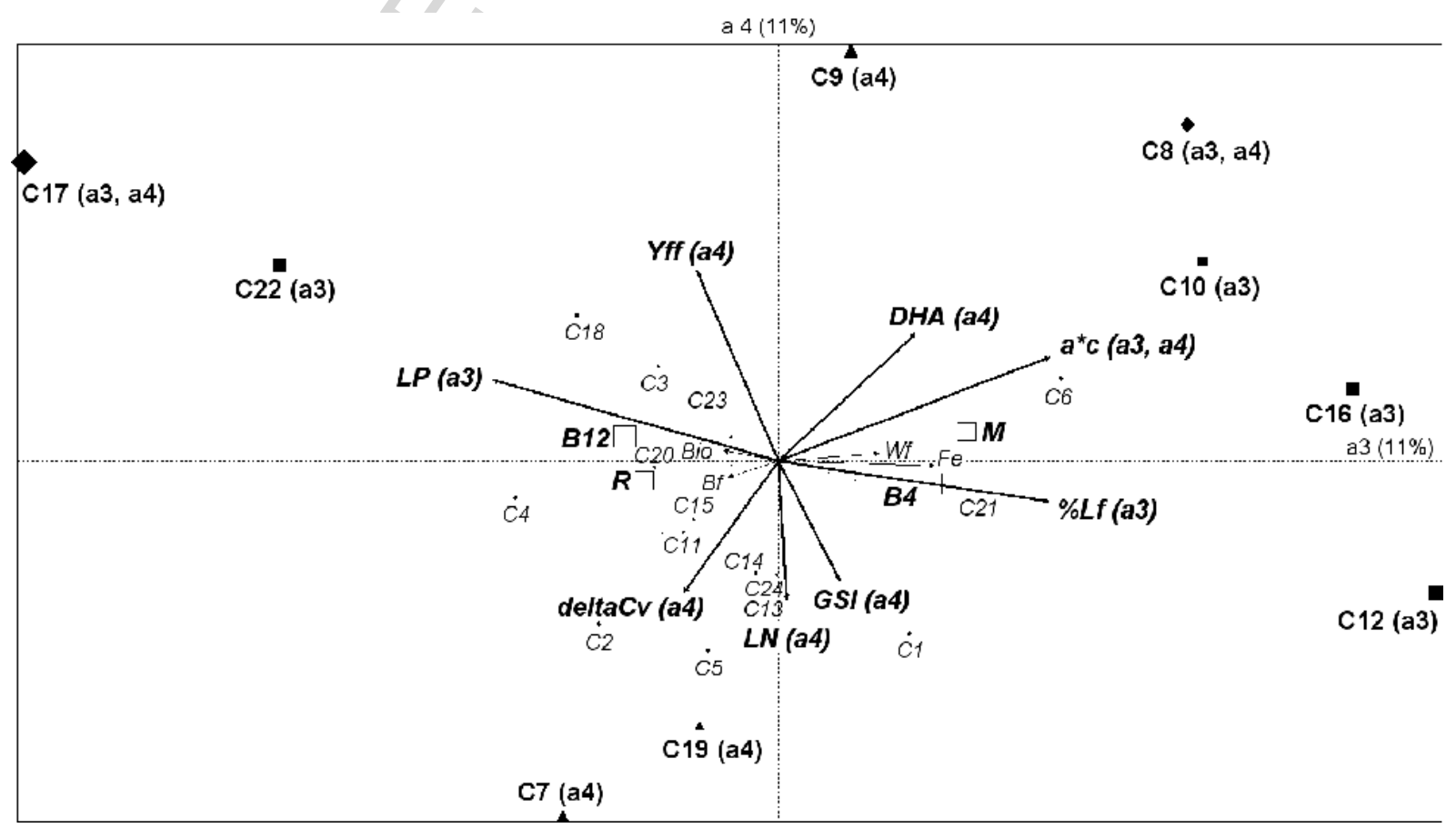


610

611

612
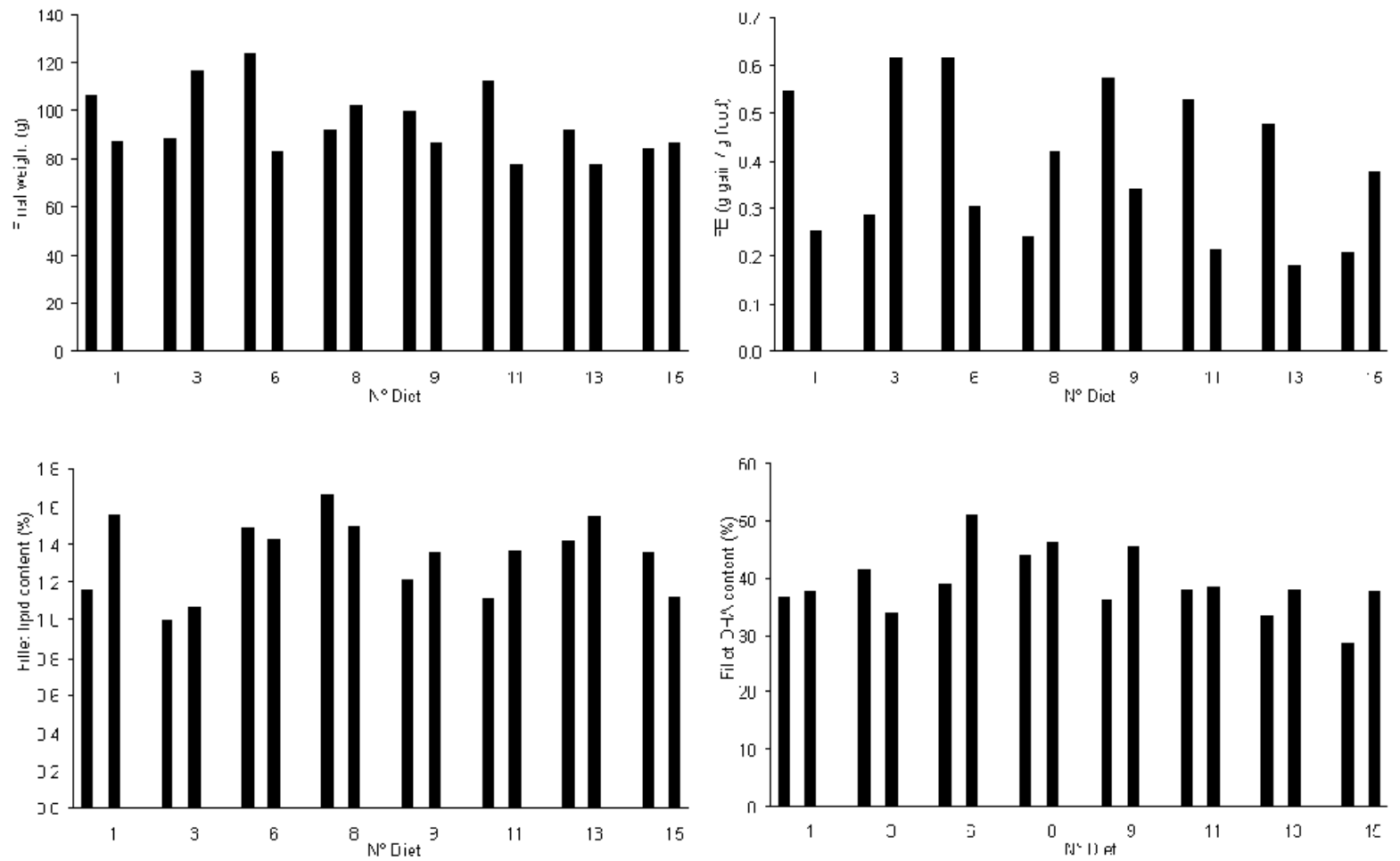

613

614

615

616 

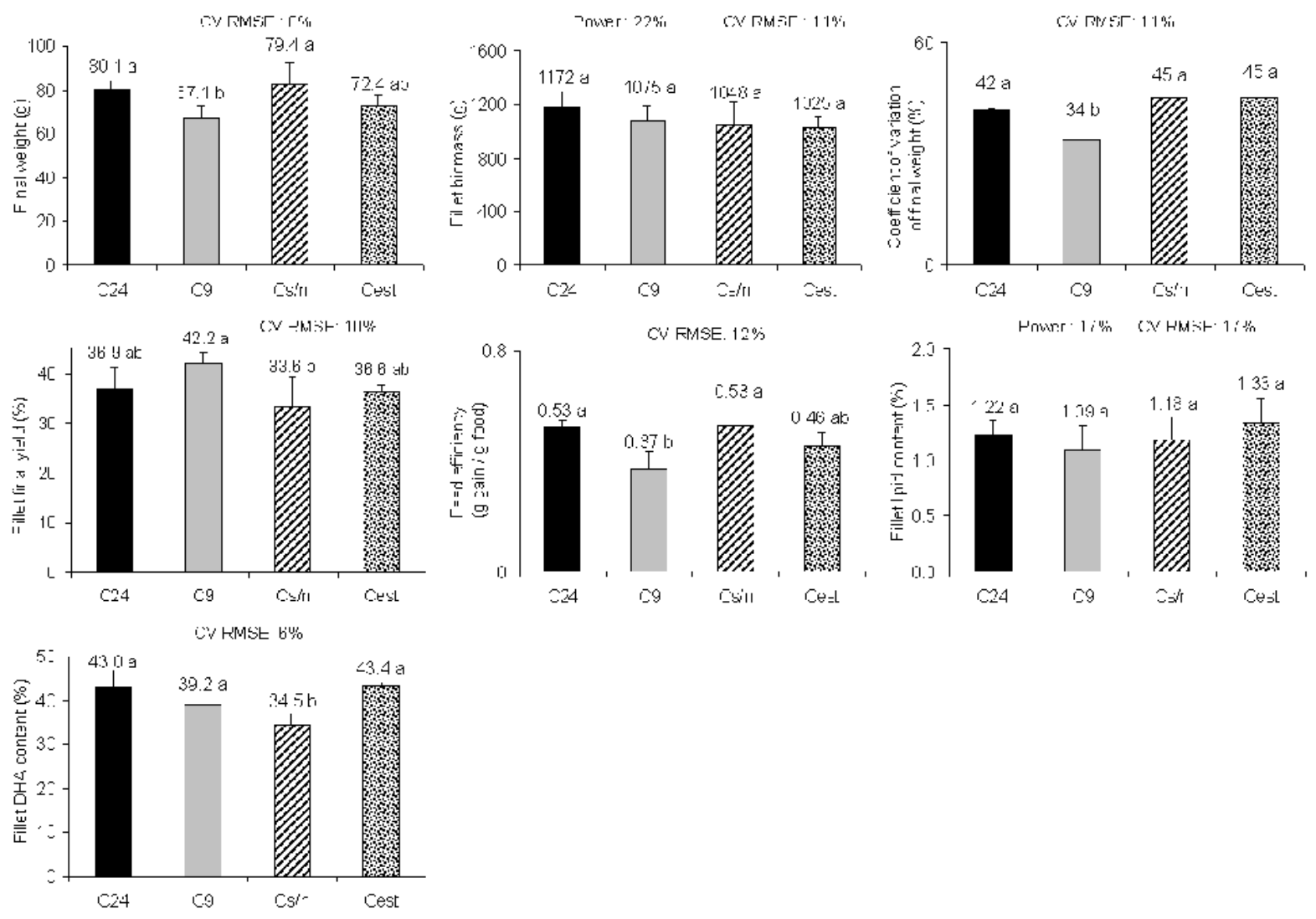